\title{
The antitumor effect of human cord blood-derived dendritic cells modified by the livin $\alpha$ gene in lung cancer cell lines
}

\author{
HAO CHEN $^{1,2}$, YANG JIN ${ }^{1,2}$, TING CHEN $^{1,2}$, MINGQIANG ZHANG ${ }^{1,2}$, \\ WANLI MA $^{1,2}$, XIANZHI XIONG ${ }^{1,2}$ and XIAONAN TAO ${ }^{1,2}$ \\ ${ }^{1}$ Department of Respiratory Diseases, Union Hospital, Tongji Medical College, \\ Huazhong University of Science and Technology, Wuhan; ${ }^{2}$ Key Laboratory of Pulmonary \\ Diseases of the Ministry of Health of China, Wuhan, Hubei 430022, P.R. China
}

Received August 1, 2012; Accepted August 16, 2012

DOI: $10.3892 /$ or.2012.2133

\begin{abstract}
The growth of malignant tumors is associated with mechanisms of immune escape and inhibition of apoptosis. Livin is a novel member of the inhibitors of apoptosis (IAP) protein family that inhibits cell apoptosis. Livin is specifically expressed by the majority of tumor cells, but it is not expressed in normal adult tissues. In this study, we used umbilical cord blood (UCB)-derived dendritic cells (DCs) infected with a recombinant adenovirus encoding the livin gene as a vaccine to activate effector cells such as cytotoxic $\mathrm{T}$ lymphocytes (CTLs) to recognize and kill livin-expressing cancer cells in vitro as an improved strategy for overcoming the ability of these cancer cells to escape apoptosis and antitumor immune responses. We employed interferon- $\gamma(\mathrm{IFN}-\gamma)$ enzyme-linked immunospot assays to confirm that our immunization strategy induced an antigen-specific reaction to livin and flow cytometric analysis of staining with Annexin V and PI to measure the cytotoxic activity of the effector cells against the livinexpressing lung cancer cell lines A549 and H460. Our results show that the recombinant adenovirus was able to promote the maturation of the UCB-derived DCs. This DC vaccine could activate antigen-specific T cells to produce IFN- $\gamma$ upon recognition of livin peptide in the context of the appropriate HLA molecule. The antigen-specific $\mathrm{T}$ cells mediate significant cytotoxicity against the cancer cells, but are unlikely to cause an autoimmune reaction against the human bronchial epithelia cells (HBE), which do not express livin.
\end{abstract}

\section{Introduction}

The acquisition of resistance to apoptosis and the ability to escape from immunological surveillance are the hallmarks of tumor cells $(1,2)$. The inhibitors of apoptosis proteins

Correspondence to: Professor Xiaonan Tao, Department of Respiratory Diseases, Union Hospital, Tongji Medical College, Huazhong University of Science and Technology, Wuhan, Hubei 430022, P.R. China

E-mail: taoxn2004@yahoo.com.cn

Key words: livin $\alpha$ gene, DC vaccine, recombinant adenovirus, lung cancer
(IAPs) inhibit apoptosis by interacting with the pro-apoptotic caspases via their baculoviral IAP repeat (BIR) (3). Previous studies indicated that downregulating the expression of IAPs is beneficial to the treatment of cancer and may be a necessary component of the antitumor activities of conventional treatments such as radiation and chemotherapy (4-6). Livin is a novel member of the IAP family; it has two isoforms that are termed livin $\alpha$ (298-amino acid residues) and livin $\beta$ (280amino acid residues). Each isoform contains a single BIR domain and a RING finger domain (7). In contrast to other members of the IAP family, such as cIAP-1, cIAP-2, XIAP and NAIP, which are expressed at low levels in normal adult tissues, livin is not expressed in normal adult tissues but is overexpressed in primary lung cancer and other malignant tumor cells $(8,9)$. Livin expression levels correlate to some degree with the stage and pathological type of the cancer, and livin expression can induce tumor cells to become resistant to antineoplastic drugs and are characteristic of a cancer with a poor prognosis (9-12). Evidence suggests that interfering with either the expression of the livin gene or the function of the livin protein could provide a potential therapeutic avenue to induce apoptosis in tumor cells and to significantly improve antitumor responses (13-15).

Since anti-livin autoantibodies have been identified in the serum of the majority of cancer patients, immunologic tolerance to livin is thought to be very weak $(16,17)$, making livin a promising candidate target for immunotherapy. Dendritic cells (DCs) are classic antigen-presenting cells (APCs) and can efficiently take up and present tumor antigens as well as provide the co-stimulatory molecules required to activate naive $\mathrm{T}$ lymphocytes $(18,19)$. In addition to antigen modulation and immune evasion (20), cancer cells may cause DCs to downregulate their expression of MHC class I molecules when the two cell types are co-cultured (21). This reduces the ability of the DCs to activate $\mathrm{CD}^{+} \mathrm{T}$ cells and leads to immune escape. In the present study, we showed that DCs that have been modified to express the livin $\alpha$ gene could provide stable presentation of livin epitopes and could induce T-cell activation. We developed a cell-transfer therapy based on these observations in which pre-sensitized tumor-specific effector cells were expanded in vitro and transplanted into 
autologous hosts $(22,23)$. Umbilical cord blood (UCB) is a rich source of hematopoietic stem cells (24) and is resistant to replicative senescence and immunosenescence (25). HLA-mismatched cord blood-derived transplants are associated with a lower incidence and severity of acute or chronic graft-versus-host disease (GVHD) (26). Thus, UCB cells are an ideal source of cells for allogeneic antitumor transplants (27). Due to the biological activity of livin, we used a replication-defective recombinant adenovirus ( $\mathrm{rAd})$ vector encoding the livin $\alpha$ gene to infect UCB-derived DCs to generate an antigen-specific vaccine that can be applied to cancer immunotherapy (28-30).

Hariu et al demonstrated that stimulating the peripheral blood lymphocytes (PBMCs) of HLA-A24+ lung cancer patients in vitro with livin peptides in the context of matched HLA molecules induced peptide-specific cytotoxic $\mathrm{T}$ lymphocytes (CTLs) that showed cytotoxicity against livin-expressing lung cancer cell lines in an HLA-A24-restricted manner (11). However, the previous study could not be universally applied in oncotherapy in individuals with various HLA subtypes as the livinexpressing DC vaccine generated responses that were restricted to the HLA-A24 MHC subtype. We previously confirmed that human livin $\alpha$ gene-modified DC vaccines can induce tumor-specific CTLs and mount significant anti-Lewis lung cancer responses in mice (28). In addition to CTLs, there are multiple cell types in the human immune system that can mediate non-specific antitumor effects, such as macrophages, NK and LAK cells $(31,32)$. In this study, we expanded on previous work to show that livin $\alpha$ gene-modified DC vaccines derived from UCB can activate multiple innate effector cell types in the human immune system in addition to CTLs to exert antitumor effects.

\section{Materials and methods}

Cell lines and culture media. The lung cancer cell lines A549 and H460 (HLA-A2 ${ }^{+} / \mathrm{A}_{24} 4^{+}$) were established in the Laboratory Center of the Union Hospital, Tongji Medical College, Huazhong University of Science and Technology, Wuhan, China. HBE cells (HLA-A2 ${ }^{+} / \mathrm{A} 24^{-}$) were kindly provided by Dr Shanshan Song (Department of Pathophysiology, Tongji Medical College, Huazhong University of Science and Technology). HEK-293 cells were purchased from AGTC Gene Technology Company Ltd., Beijing, China. A549 and H460 cells were maintained in RPMI-1640 while HBE and HEK cells were maintained in DMEM. Both culture media were supplemented with $10 \%$ heat-inactivated fetal bovine serum (HyClone; Thermo Scientific, Waltham, MA, USA), $2 \mathrm{mM}$ L-glutamine, $1 \mathrm{mM}$ sodium pyruvate, $100 \mathrm{U} / \mathrm{ml}$ penicillin and $100 \mu \mathrm{g} / \mathrm{ml}$ streptomycin (all from Sigma, St. Louis, $\mathrm{MO}, \mathrm{USA}$ ) in a humidified incubator at $37^{\circ} \mathrm{C}$ with $5 \% \mathrm{CO}_{2}$.

Construction of recombinant adenoviral vector encoding the livin a gene. Replication-defective type-5 adenoviruses (rAd5) in which the E1 and E3 region were deleted and that encoded enhanced green fluorescent protein (EGFP) were used as vectors in this study. Our lab used the shuttle plasmid pDC316-EGFP-cmv-livin $\alpha$, which was synthesized by Dr Junping Xie. The helper plasmid pBHGlox_E1,3Cre was purchased from AGTC Gene Technology Company Ltd. HEK-293 cells were co-transfected with the shuttle plasmid and the helper plasmid to produce the recombinant adenovirus.

After three rounds of amplification, the crude lysates were purified by density gradient centrifugation and dialysis. The titer of the rAd-livin $\alpha$ was calculated using the 50\% tissue culture infective dose $\left(\mathrm{TCID}_{50}\right)$ assay.

$P C R$. Polymerase chain reaction (PCR) was used to evaluate whether the rAd-livin $\alpha$ vector had been generated successfully. We utilized an empty rAd vector as a negative control and pDC316-EGFP-cmv-livin $\alpha$ as a positive control. Briefly, amplification was performed in $25 \mu 1$ of PCR mixture containing $1 \mu \mathrm{l}$ of the template, $0.5 \mu \mathrm{l}$ of primers $(50 \mu \mathrm{M})$ and $0.25 \mu \mathrm{l}$ of Taq DNA polymerase. The PCR mixture was initially incubated at $94^{\circ} \mathrm{C}$ for $4 \mathrm{~min}$, followed by 30 cycles of denaturation at $94^{\circ} \mathrm{C}$ for $30 \mathrm{sec}$, annealing at $56^{\circ} \mathrm{C}$ for $40 \mathrm{sec}$ and extension at $70^{\circ} \mathrm{C}$ for $50 \mathrm{sec}$, followed by a final extension at $72^{\circ} \mathrm{C}$ for $10 \mathrm{~min}$. PCR products were analyzed by electrophoresis on a $1 \%$ agarose gel.

The forward primer 5'-GCCATGGGGCCTAAAGACA GTG-3' and the reverse primer 5'-CTGCTAGGACAGGAAG GTGCG-3' were used according to the manufacturer's protocol for the specific detection of livin $\alpha$. The expected size of PCR product for livin $\alpha$ is $897 \mathrm{bp}$.

Isolation and induction of UCB-derived DCs in vitro. Heparin anti-coagulated (20 U/ml) HLA-A2 ${ }^{+} / \mathrm{A} 24^{-}$and HLA-A2 ${ }^{+} / \mathrm{A}^{-} 4^{+}$ UCB samples were isolated following cesarean sections with the approval of the ethics committee of the Tongji Medical School, Huazhong University of Science and Technology. All patients provided informed consent prior to the surgery, which was performed at the Obstetrics Department, Wuhan Union Hospital, China. The HLA class was determined using polymerase chain reaction with sequence-specific primers (PCR-SSP).

We generated UCB-derived DCs in vitro using a combination of previously described protocols (33-36). Briefly, mononuclear cells (MNC) were obtained using a FicollHypaque (TBD Biotechnology developing center, relative density 1.077 at $20^{\circ} \mathrm{C}$ ) density gradient. The precursor DCs were isolated using anti-CD34 microbeads (Miltenyi Biotec, Bergisch Gladbach, Germany). These cells were cultured in RPMI-1640 medium supplemented with $20 \%$ FBS. The culture media were also supplemented with $50 \mathrm{ng} / \mathrm{ml}$ of GM-CSF (PeproTech Inc., Rocky Hill, NJ, USA), $50 \mathrm{ng} / \mathrm{ml}$ of SCF (PeproTech) and $20 \mathrm{ng} / \mathrm{ml}$ of IL-4 (PeproTech) to induce the development of UCB-derived DCs. Half of the culture medium was replaced with fresh medium containing the appropriate concentration of cytokines every other day.

The cultured cells were then separated into adherent cells and non-adherent fractions and the non-adherent cells were supplemented with $100 \mathrm{U} / \mathrm{ml}$ of IL-2 (Peprotech) to induce the development of effector cells, which were predominantly CTLs.

Preparation of the stimuli and DC vaccines. On Day 5, DCs were harvested and washed with RPMI-1640 medium, then 
pulsed with a variety of tumor-associated antigens (TAAs), either rAd-livin $\alpha$ or rAd-c at a multiplicity of infection (MOI) of 200, and $30 \mu \mathrm{g} / 10^{6}$ cells of A549 and H460 lysates that had undergone 3 cycles of freezing and thawing between -80 and $37^{\circ} \mathrm{C}$ and had been passed through a $0.22-\mu \mathrm{m}$ filter. The cultures were incubated for $2 \mathrm{~h}$ in $0.3 \mathrm{ml}$ of serum-free medium supplemented with GM-CSF and IL-4 but not SCF, then supplemented with complete medium. On Day 7,50 ng/ml GM-CSF, $20 \mathrm{ng} / \mathrm{ml} \mathrm{IL-4,} 10 \mathrm{ng} / \mathrm{ml}$ TNF- $\alpha$ (all PeproTech) and $1 \mu \mathrm{g} / \mathrm{ml}$ PGE (Sigma) were added to the cultures to induce DC maturation and the cells were cultured for an additional 2 days.

On Day 9, IL-2-induced cells were co-cultured with mature DCs at a ratio of 10:1 in culture medium supplemented with IL-2 and IL-12 (PeproTech). The cells were cultured together for an additional $48 \mathrm{~h}$ before the cytotoxic activity of the effector cells was measured.

Evaluation of the infection efficiency of restructured adenoviruses in DCs and cell viability. DCs infected rAd at MOI 50, 100, 200 and 400. As the viral vector was modified to encode EGFP, the efficiency of infection can be correlated to the proportion of EGFP-positive cells detected by flow cytometry. Viable cells cannot be stained with trypan blue and trypan blue staining was used to evaluate cell viability.

Differentiation and maturation of DC cells measured by flow cytometry. The expression of DC cell surface molecules (CD1a, CD80, CD86 and HLA-DR) was analyzed by flow cytometry. The DC cells were divided into precursor DC cells, mature DC cells, and DC cells infected with either rAd-control or rAd-livin $\alpha$. Cells were harvested and incubated with monoclonal antibodies (anti-human CD86 Alexa Fluor 488, anti-human CD80 PE-Cy5, anti-human CD1a PE and anti-human HLA-DR APC) (eBioscience Inc., San Diego, $\mathrm{CA}, \mathrm{USA}$ ) at $4^{\circ} \mathrm{C}$ for $30 \mathrm{~min}$. The lysates were centrifuged at $1,000 \mathrm{rpm}$ for $6 \mathrm{~min}$, the supernatant was then discarded and the cells were washed with PBS. The cells were centrifuged again at 1,000 rpm for $6 \mathrm{~min}$, then fixed in $4 \%$ paraformaldehyde and analyzed by flow cytometry.

Western blot analysis. We used western blots to analyze livin expression in H460, HBE and A549 cells, in rAd-c-infected and rAd-livin $\alpha$-infected DCs and in MNCs. Amino acids 264-280 of the short isoform or amino acids 281-298 of the long isoform of human livin (Abcam, Cambridge, MA, USA) were used as positive controls. Cells were lysed in lysis buffer (12.5 mM HEPES, $200 \mathrm{mM} \mathrm{KCl,} 5 \mathrm{mM}$ EDTA, $50 \mathrm{mM} \mathrm{NaF}$, $0.5 \% \mathrm{NP}-40,0.5 \mathrm{mM}$ PMSF, $5 \mu \mathrm{g} / \mathrm{ml}$ leupeptin, $5 \mu \mathrm{g} / \mathrm{ml}$ aprotinin and $2 \mathrm{mM} \mathrm{Na}_{3} \mathrm{VO}_{4}$ ). The protein content of the supernatant was determined using the Bio-Rad Protein Assay kit. Whole cell extract $(50 \mu \mathrm{g})$ was denatured in SDS sample buffer and loaded onto a $12 \%$ SDS-PAGE gel.

Following electrophoresis, the proteins were transferred to PVDF membranes. The membranes were blocked with $5 \%$ non-fat milk in Tween-20 in TBS (TBST, $15 \mathrm{mM}$ Tris- $\mathrm{HCl}$, $\mathrm{pH} 7.5,200 \mathrm{mM} \mathrm{NaCl}$ and $0.1 \%$ Tween-20) for $2 \mathrm{~h}$ at room temperature. Subsequently, the membranes were incubated overnight with a rabbit anti-livin polyclonal antibody (Abcam) at $4^{\circ} \mathrm{C}$. The primary antibodies were detected using a horse- radish peroxidase (HRP)-conjugated secondary antibody (Santa Cruz Biotechnology, Santa Cruz, CA, USA). The signal was detected by treating the membrane with ECL reagent and exposing it to X-ray film. Protein loading was assessed by GAPDH.

IFN- $\gamma$ ELISPOT assays. An IFN- $\gamma$ ELISPOT assay was performed to detect livin-specific effector T cells (37). According to the manufacturer's instructions, UCB-derived effector cells were resuspended in Lympho-Spot ${ }^{\mathrm{TM}}$ serum free medium at a final concentration of $1.0 \times 10^{6}$ cells $/ \mathrm{ml}$.

Lympho-Spot serum free medium (200 $\mu \mathrm{l} /$ well) was added to 48-well PVDF plates (DKW, China) that had been pre-coated with anti-IFN- $\gamma$ antibody. After $10 \mathrm{~min}$, the serum free medium was replaced and the effector cells were moved to suspension cultures in plates $\left(1.5 \times 10^{5}\right.$ cells/well $)$. The cells were then stimulated with a final concentration of $10 \mu \mathrm{g} / \mathrm{ml}$ of either a livin polypeptide (KWFPSCQFLL) or a livinunrelated polypeptide (RYLRDQQLLGI), both of which have previously been demonstrated to be restricted to HLA-A24 (11). Lympho-Spot serum free medium alone was used as a negative control and PHA (plant hemagglutinin, $2 \mu \mathrm{g} / \mathrm{ml}$ ) was used as a positive control. The PVDF plates were placed in a humidified incubator at $37^{\circ} \mathrm{C}$ for $20 \mathrm{~h}$. The media were then removed from the plates and the cells were lysed with cold $\mathrm{ddH}_{2} \mathrm{O}$. After washing the plates, each well was incubated first with biotinylated anti-IFN- $\gamma$ antibody (100 $\mu \mathrm{l} /$ well $)$ and then with streptavidin-HRP $(100 \mu \mathrm{l} /$ well $)$ at $37^{\circ} \mathrm{C}$ for $1 \mathrm{~h}$. Then, the PVDF plates were treated with AEC (100 $\mu \mathrm{l} / \mathrm{well})$ at room temperature in the dark for $25 \mathrm{~min}$. After washing with $\mathrm{dd}_{2} \mathrm{O}$, the number of spot-forming cells (SFC) was analyzed using a Biosys-Bioreader. The results are expressed as $\mathrm{SFC} / 10^{5}$ effector cells $=(\mathrm{SFC}$ number/well $) \times 10^{5} /$ (number of cells/well).

Cytotoxicity assay. The cytotoxic activity of the effector cells was measured by flow cytometry as previously described (38-41). Briefly, the target cells were resuspended in PBS supplemented with $0.1 \%$ BSA at a final concentration of $2 \times 10^{6}$ cells $/ \mathrm{ml}$. The target cells were incubated in $1 \mu \mathrm{M} \mathrm{CFSE}$ at $37^{\circ} \mathrm{C}$ for $10 \mathrm{~min}$. Then, 5 volumes of icecold culture media were added to quench the staining. The CFSE-stained target cells were centrifuged, resuspended and mixed with the effector cells at effector/target ratios of 5:1, 10:1 and 20:1. The cells were co-cultured in a humidified incubator at $37^{\circ} \mathrm{C}$ with $5 \% \mathrm{CO}_{2}$.

After $4 \mathrm{~h}$, the cells were resuspended, incubated with $5 \mu \mathrm{l}$ of Annexin V-APC and $5 \mu \mathrm{l}$ of PI and examined by flow cytometry. Annexin V staining was assessed on CFSEpositive cells to measure target cell death. Annexin $\mathrm{V}^{-} / \mathrm{PI}^{+}$cells were defined as necrotic and were excluded from the analysis. The percentage of specific lysis was calculated as follows: (\% experimental lysis - \% basal lysis)/(\% maximum lysis - \% basal lysis) x 100 .

Statistical analysis. Values are expressed as the means \pm SE. Statistical analysis was performed using the Student's $\mathrm{t}$-test or one way analysis of variance (ANOVA). Values of $\mathrm{P} \leq 0.05$ were considered to indicate statistically significant differences. 

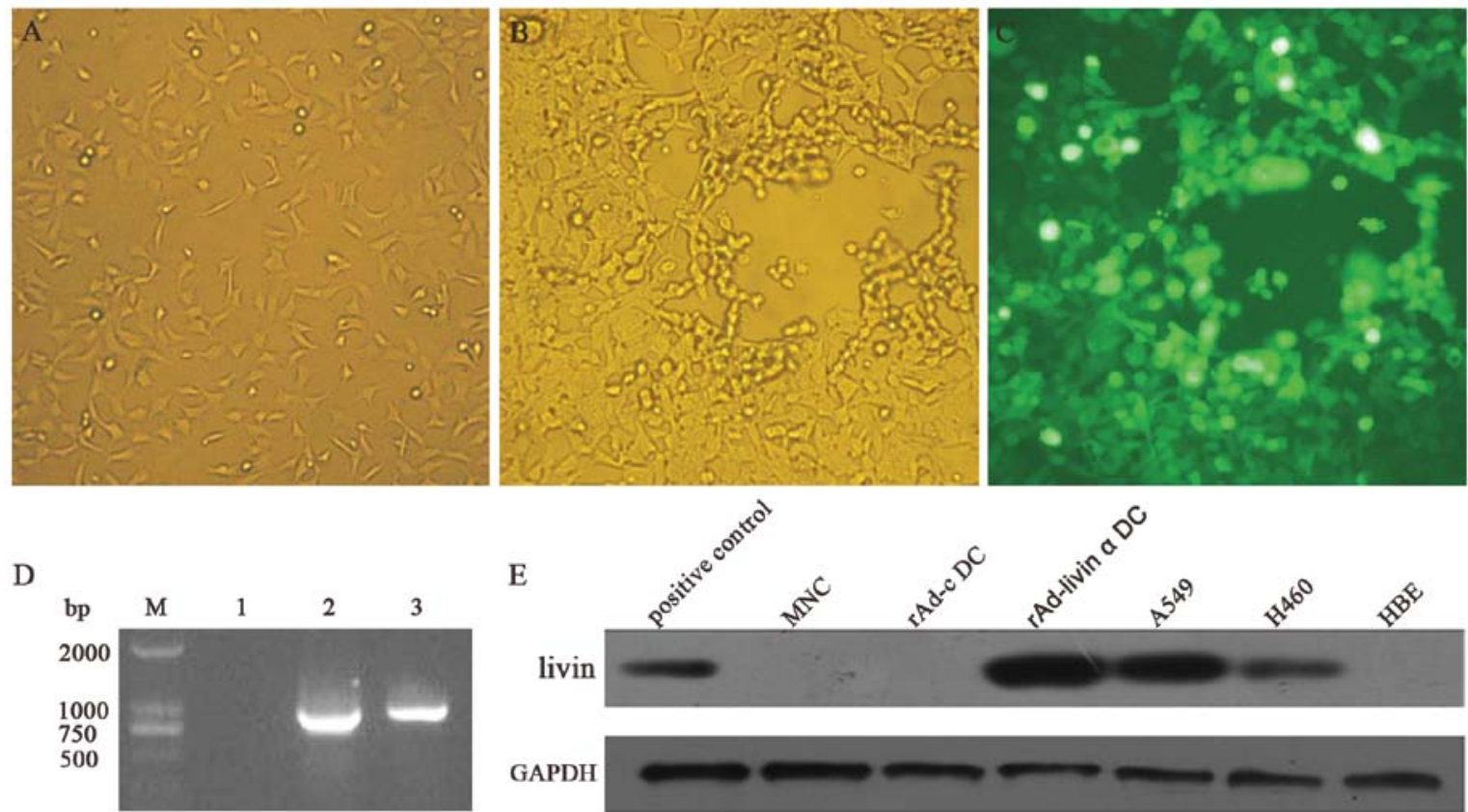

Figure 1. Construction and identification of rAd-livin $\alpha$. (A) HEK-293 cells before co-transfection (magnification, x200). (B) HEK-293 cells show typical CPE after co-transfection, (magnification, x200). (C) GFP expression was detected after the infection of HEK-293 cells with rAd-livin $\alpha$ (magnification, x200). (D) Identification of rAd-livin $\alpha$ by PCR. Lane M, DNA ladder marker; lane 1, empty adenovirus as a negative control; lane 2, pDC316-EGFP-cmv-livin $\alpha$ as a positive control; lane 3, rAd-livin $\alpha$. (E) Western blot analysis of livin protein expression in NMCs, rAd-c-infected DCs, rAd-livin $\alpha$-infected DCs, A549, H460 and HBE cells.
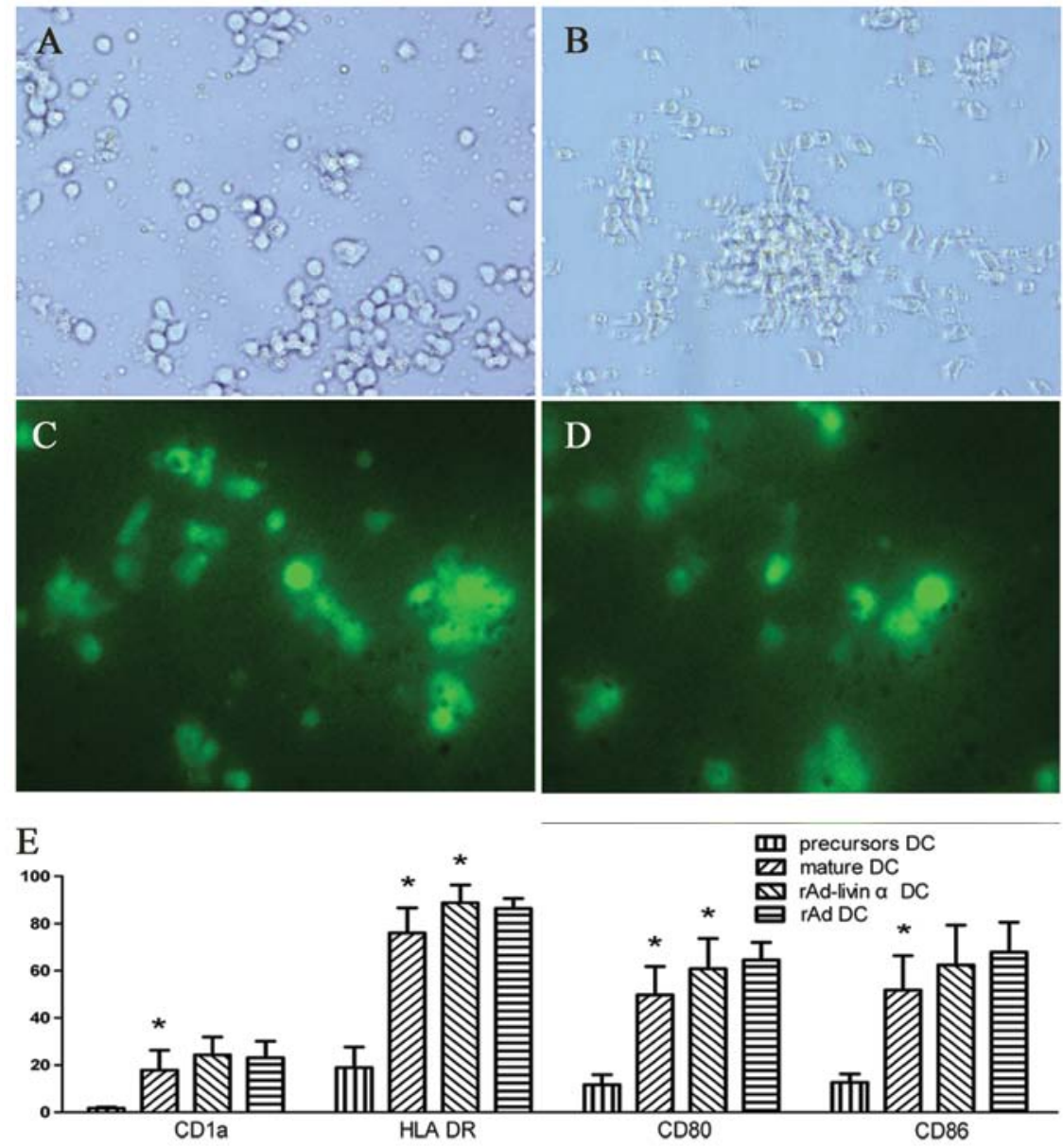

Figure 2. Morphology of and surface marker expression on DCs. (A) DC precursors, (B) mature DCs, (C) rAd-c-infected DCs, (D) rAd-livin $\alpha$-infected DCs, (magnification, x400). (E) Expression levels of cell surface molecules on DCs (CD1a, CD80, CD86, HLA-DR). Data are presented as the means \pm SD of 3 separate tests by ANOVA. ${ }^{*} \mathrm{P}<0.05$. 


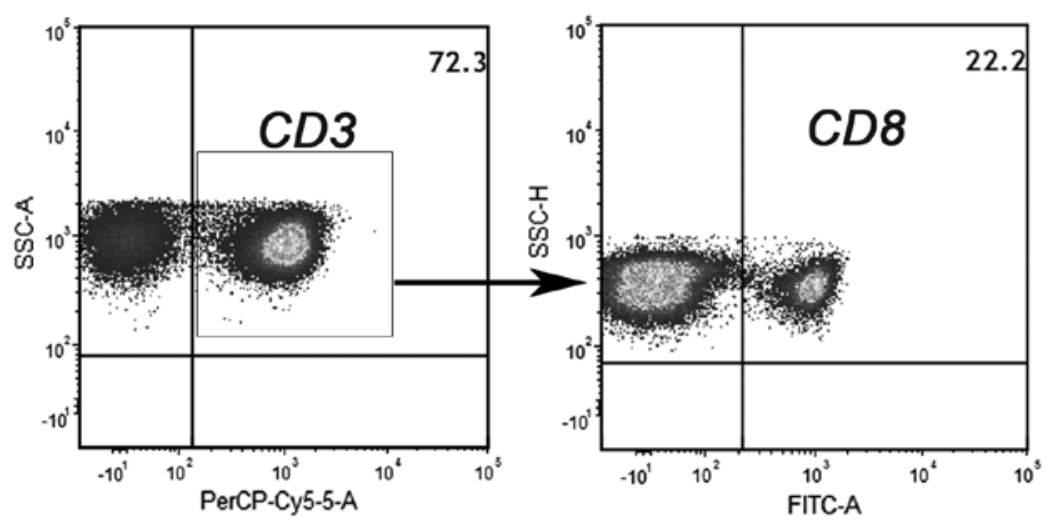

Figure 3. CD3 staining on effector cells. Gating on the CD3 positive T cells (72.3\%), 22.2\% were CD8 positive and the others (77.8\%) were considered to be CD4 positive $\mathrm{T}$ cells.

\section{Results}

Verification of adenovirus encoding the livin a gene. Seven days after co-transfecting HEK-293 cells (Fig. 1A) with the shuttle plasmid pDC316-EGFP-cmv-livin $\alpha$ and the backbone plasmid pBHGlox_E1,3Cre, the cells acquired an appearance typical of cytopathic effects (CPE) and viral plaques were visible under microscopic examination (Fig. 1B). Moreover, the cells appeared beaded and to have undergone botryoid changes, and the majority of the cells had detached from the surface of the plate. The expression of green fluorescent protein was visualized using a fluorescent microscope (Fig. 1C), and the results indicated that the recombination adenovirus had successfully infected the target cells and that the adenovirus encoded genes were being expressed.

The target gene detected by PCR was consistent with the expected gene livin $\alpha$ (897 bp) (Fig. 1D). The titer of the rAdlivin $\alpha$ was $2 \times 10^{9} \mathrm{TCID}_{50} / \mathrm{ml}$, and the titer of the rAd-control was $2 \times 10^{11} \mathrm{TCID}_{50} / \mathrm{ml}$, as determined by the TCID $_{50}$ method.

Livin is expressed in tumor cell lines and in DC cells infected by rAd-livin $\alpha$, but not in HBE cell lines or mononuclear cells. We determined the expression of endogenous protein livin in A549, H460, HBE, rAd-c DC, rAd-livin $\alpha$ DC and MNC by western blot analysis. We confirmed that the livin protein is expressed in A549 and $\mathrm{H} 460$ cells and rAd-livin $\alpha$-infected DCs, but not in HBE cells, rAd-c-infected DCs or MNCs (Fig. 1E).

Optimal MOI for recombinant adenovirus infection of DC cells. DC cells were infected with rAd-livin $\alpha$ after 7 days of culture. The expression levels of EGFP were determined by flow cytometry after $48 \mathrm{~h}$. We determined that the optimal MOI value was 200, at which $88 \%$ of the cells expressed EGFP and $69 \%$ of the cells were viable.

Expression of DC surface molecules is increased when DCs mature or are infected with adenovirus. DC precursors were isolated using anti-CD34 microbeads. Freshly isolated precursor cells were small, round, transparent and nonadherent (Fig. 2A). After 3 days of culture with cytokines, the majority of the cells developed multiple surface protrusions of various lengths. The cultured cells appeared to proliferate and to increase in size and granularity and became either adherent or semi-adherent. Over time, the cultured DC cells developed longer protrusions and a more irregular morphology. After being cultured with TNF- $\alpha$ for 3 days, the majority of DC cells became non-adherent, scattered uniformly throughout the medium, and acquired a morphology typical of mature DCs (Fig. 2B). DCs infected with either rAd-c or rAd-livin $\alpha$ fluoresced green when viewed using a fluorescent microscope (Fig. 2C and D).

The expression of CD1a, CD80, CD86 and HLA-DR are important markers of immunocompetence and maturity in DCs. As shown in Fig. 2E, DC precursors expressed low levels of CD80, CD86 and HLA-DR. The expression levels of these surface markers increased significantly when these cells were cultured in the presence of cytokines and were further increased by infection with adenovirus although this difference did not reach significance for CD1a and CD86. The mature DCs exhibited the same phenotype regardless of whether they were infected with rAd-livin $\alpha$ or rAd-c. These results suggest that infection with rAd can promote the maturation of UCB-derived DCs.

Percentage of CD4 and CD8 T-cell populations in the effector cells. After culturing the cells in the presence of IL-2, nonadherent NMCs were used as effector cells. Flow cytometric analysis revealed that $72 \%$ of the effector cells were $\mathrm{CD}^{+}$ lymphocytes. Further characterization of the T-cell subsets demonstrated that $78 \%$ of the $\mathrm{CD}^{+}$population was $\mathrm{CD} 3{ }^{+} \mathrm{CD} 8$ (CD4 T cells) and $22 \%$ of the $\mathrm{CD}^{+}$population was $\mathrm{CD}^{+} \mathrm{CD}^{+}$ (CD8 T cells) (Fig. 3).

Effector cells activated by rAd-livin $\alpha$-infected DCs respond specifically to livin polypeptides in an HLA-restricted manner. We assessed the response of $\mathrm{T}$ lymphocytes to livin polypeptides using ELISPOT assays to detect IFN- $\gamma$ production. Effector cells that had been stimulated by HLA-24 ${ }^{+}$rAd-livin $\alpha$-infected DCs and were then exposed to HLA-24 presenting livin polypeptide generated a statistically greater number of IFN- $\gamma$ spots than either cells stimulated by rAd-c-infected DCs or the blank control (Fig. 4B). By contrast, HLA-24- lymphocytes incubated with the peptide did not produce a significant 


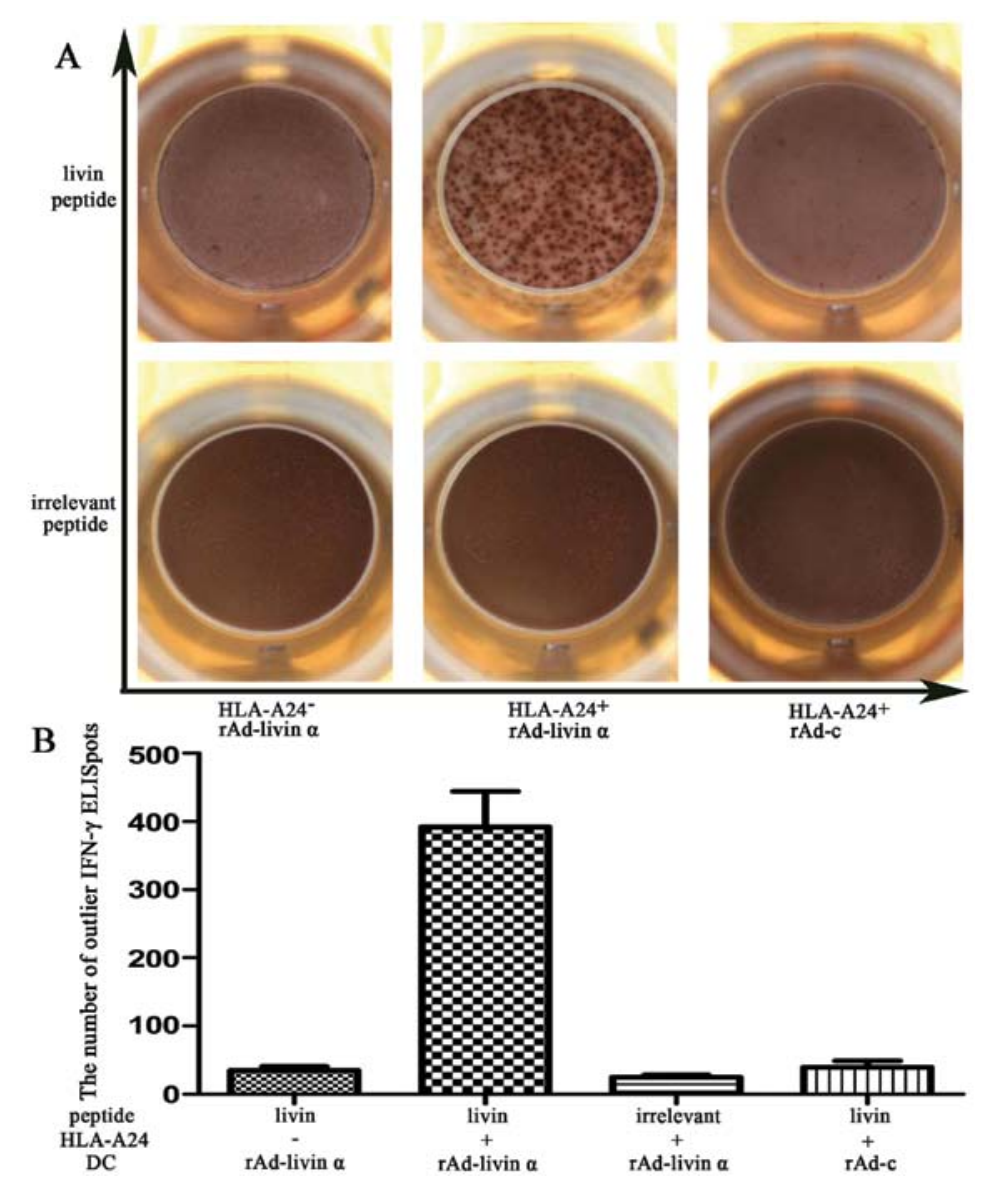

Figure 4. T lymphocytes stimulated by rAd-livin $\alpha$-infected DCs are specific for livin and livin peptide (KWFPSCQFLL) is HLA-A24 restricted. (A) IFN- $\gamma$ ELISPOT of UCB-lymphocytes primed by rAd-livin $\alpha$-infected DCs or rAd-c-infected DCs and restimulated with an HLA-A24 restricted livin peptide or irrelevant peptide. (B) ELISPOT wells are shown for comparison. $y$-axis, the number of IFN- $\gamma$ spots per 10,000 cells. Data are presented as the means \pm SD of 3 separate tests by ANOVA. $\mathrm{P}<0.05$.

number of IFN- $\gamma$ spots. Furthermore, when the effector cells were exposed to irrelevant peptides, there were very few IFN- $\gamma$ spots regardless of the HLA type, as shown in the bottom row of Fig. 4A.

rAd-livin $\alpha$-infection of DCs enhances tumor-specific CTL cytotoxicity and decreases autoimmunity. HLA-A2 ${ }^{+}$ UCB-derived DCs were pulsed with different forms of antigen from either A549 or H460 cells that had undergone multiple freeze-thaw cycles or rAd-c or rAd-livin $\alpha$ to study whether rAd-livin $\alpha$-infected DCs could enhance tumor-specific cytotoxicity against livin protein-expressing tumor cells (A549, H460) without inducing autoimmune responses against livin protein negative cells (HBE). Cytotoxicity against A549, H460 and HBE cells was examined by flow cytometry by staining for Annexin V/PI. The data are presented in Fig. 5. Effector cells stimulated with rAd-livin $\alpha$-infected DCs mediated more cytotoxicity than effector cells stimulated with rAd-c DC or the blank control at effector/target ratios of 5:1, 10:1 and 20:1. Effector cells stimulated with rAd-livin $\alpha$-infected DCs or with proteins that had undergone multiple freeze-thaw cycles mediated similar levels of cytotoxicity but effector cells stimulated with rAd-livin $\alpha$-infected DCs mediated less nonspecific cytotoxicity than those stimulated with proteins from A549 or $\mathrm{H} 460$ cells that had undergone multiple freeze-thaw cycles.

\section{Discussion}

A variety of immune cells and immune molecules participate in antitumor immune responses. CD8 ${ }^{+}$CTLs and CD4 ${ }^{+}$Th1 cells play key roles in antitumor activity (42). We propose using DCs loaded with tumor antigen as a DC vaccine to induce or enhance antitumor immune responses. CTLs require not only appropriately presented antigen and co-stimulatory signals from APCs for their activation, but also co-stimulatory signals from activated $\mathrm{CD} 4^{+} \mathrm{T}$ cells. In addition, a few $\mathrm{CD} 4^{+}$ T cells show MHC II-restricted cytotoxicity towards cancer cells (43-46). Due to these immune mechanisms and the in vivo immune environment, we chose non-adherent UCB-derived MNCs cultured with IL-2 as effector cells instead of $\mathrm{CD}^{+} \mathrm{T}$ lymphocytes sorted from MNCs. The effector cell population was composed predominantly of $\mathrm{CD} 4^{+}$and $\mathrm{CD} 8^{+} \mathrm{T}$ lymphocytes, with a minor contribution from other immune cells, which mounted weak specific cytotoxic responses against the targets.

When DC vaccines are administered either simultaneously with or sequentially in combination with other anticancer agents, they can induce synergistic antitumor activity while minimizing the toxicity to normal hematopoietic or other organs (47-49). There are several methods to load DCs with tumor antigens. DC cells can either be pulsed with tumor-associated antigens (TAAs) or tumor cell lysates or be modified to 
A
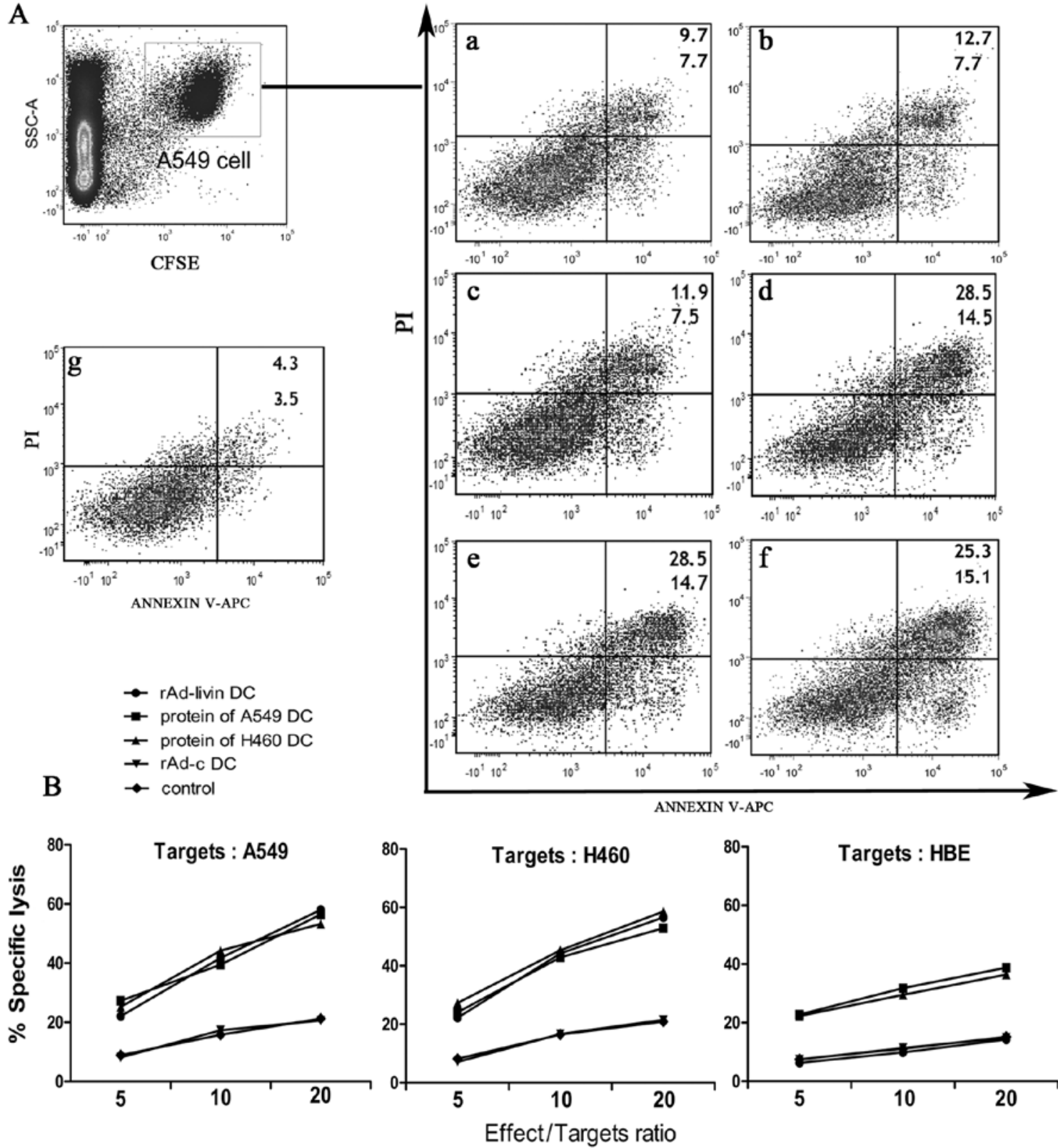

Figure 5. Cytotoxicity assays of various forms of the DC vaccines. (A) Plots are gated on the CFSE-labeled target cells. For simplicity, an E:T ratio of 10:1 is shown in the figures. (a and b) The cytotoxicities of the primitive T cells against A549 and HBE cells. (c and d) The cytotoxicity of the effector cells stimulated by rAd-c-infected DCs and rAd-livin-infected DCs against the A549 cells. (e and f) The cytotoxicity of the effector cells stimulated by rAd-livin-infected DCs and A549 lysate-pulsed DCs against H460 and HBE cells, respectively. (g) Background levels of apoptosis of A549 cells. (B) The cytotoxicity assay at E:T ratios of 5:1, 10:1 and 20:1. Data are presented as the means \pm SD of 3 separate tests by ANOVA.

express TAA genes (30,50-52). Tumor proteins are known to be involved in the degradation and recycling of MHC molecules and tumor-associated polypeptides are only weakly immunogenic in the context of HLA restriction. Tumor cell extracts also contain typical host antigens and may induce autoimmune response when used as vaccines (53). In the present study we showed that although DC cells pulsed with lysates from A549 or H460 cells can activate lymphocytes and induce a strong cytotoxic response against A549 or $\mathrm{H} 460$ cells, they also induce the significant non-specific killing of HBE cells. This indicates that unmodified proteins, polypeptides or tumor cell extracts may not be optimal for making DC vaccines. A key goal in cancer immunotherapy is to present TAA in an appropriate form that can be widely applied to induce anti-tumor immunity.
It is not sufficient that the peptide epitope be recognized by an allo-reactive CTL; it is important to target tumor antigens that play a key role in the growth and metabolism of malignant tumors. As the livin protein contributes directly to the phenotype of malignant tumors, it is a rational target for novel therapeutic strategies. As livin $\alpha$ contains virtually all the antigenic epitopes of livin $\beta$, we infected DCs with rAd-livin $\alpha$. Our strategy allows the DCs to express the livin protein endogenously, process it and present it in the context of MHC I to activate CTLs. Furthermore, we observed that infection with rAd can promote DC maturation and enhance their expression of co-stimulatory molecules $(28,46,54)$.

$\mathrm{T}$ lymphocytes specifically recognize antigen peptides presented by APCs in the context of MHC I molecules and 
become activated and secrete cytokines (55). The IFN- $\gamma$ ELISPOT assay shows that homologous effector cells sensitized by rAd-livin $\alpha$-infected DCs respond specifically to livin polypeptide presented in the context of the appropriate HLA molecules. HLA-A24\%HLA-A $2^{+} \mathrm{T}$ cells that had been sensitized by rAd-livin $\alpha$-infected DCs were able to recognize and kill A549 and H460 cells. We hypothesize that rAd-livin $\alpha$-infected DCs expressing the complete livin gene present a wide variety of molecular epitopes in the context of MHC I, so the rAd-livin $\alpha$-infected DCs may also present other HLA-restricted livin antigens in either HLA-A2 or other HLA subtypes. Thus, rAd-livin $\alpha$-infected DCs could be widely applied to the treatment of cancer, regardless of HLA subtype.

The cytotoxicity test demonstrated that all target cells were susceptible to a low level of non-specific killing by effector cells. In addition to activated CTLs, there are other types of effector cells that can exert nontumor antigen-specific or MHC-restricted cytolytic activity against the tumors, which include macrophages, NK cells and LAK cells. The relatively small number of apoptotic cells observed in the control wells indicates that the majority of cytolytic activity is mediated by the CTLs and Th1 cells, rather than by the NK cells or the macrophages. As shown in Fig. 4, homologous effector cells sensitized by rAd-livin $\alpha$-infected DCs show significant cytotoxicity against A549 and H460 cells, but only moderate cytotoxicity against HBE cells. Effector cells stimulated with rAd-livin $\alpha$-infected DC demonstrated the same level of cytotoxicity against HBE cells as the control, indicating that effector cells alone are mildly non-specifically cytotoxic to HBE cells.

The present study demonstrated for the first time that UCB-derived DCs infected with rAd-livin $\alpha$ can sensitize autologous $\mathrm{T}$ lymphocytes to effectively kill livin-expressing tumor cells without inducing autoimmunity against normal tissue. This antitumor strategy shows great potential, but needs to be studied further in vivo. In particular, the antitumor effect of UCB-derived rAd-livin $\alpha$-infected DC vaccines in allogenic cancer patients warrants further study.

\section{Acknowledgements}

This study was supported by the Hubei Key Laboratory of Biological Targeted Therapy.

\section{References}

1. Cramer DW and Finn OJ: Epidemiologic perspective on immunesurveillance in cancer. Curr Opin Immunol 23: 265-271, 2011.

2. Kruyt FAE and Schuringa JJ: Apoptosis and cancer stem cells: implications for apoptosis targeted therapy. Biochem Pharmacol 80: 423-430, 2010

3. Vaux DL and Silke J: IAPs, RINGs and ubiquitylation. Nat Rev Mol Cell Biol 6: 287-297, 2005.

4. Li XF, Gong RY, Wang M, et al: Sorafenib down-regulates c-IAP expression post-transcriptionally in hepatic carcinoma cells to suppress apoptosis. Biochem Biophys Res Commun 418: 531-536, 2012.

5. Ndubaku C, Varfolomeev E, Wang L, et al: Antagonism of c-IAP and XIAP proteins is required for efficient induction of cell death by small-molecule IAP antagonists. ACS Chem Biol 4: 557-566, 2009.

6. Berger R, Jennewein C, Marschall V, et al: NF-kappaB is required for Smac mimetic-mediated sensitization of glioblastoma cells for gamma-irradiation-induced apoptosis. Mol Cancer Ther 10: 1867-1875, 2011.
7. Ashhab Y, Alian A, Polliack A, Panet A and Ben Yehuda D: Two splicing variants of a new inhibitor of apoptosis gene with different biological properties and tissue distribution pattern. FEBS Lett 495: 56-60, 2001

8. Wagener N, Crnkovic-Mertens I, Vetter C, et al: Expression of inhibitor of apoptosis protein Livin in renal cell carcinoma and non-tumorous adult kidney. Br J Cancer 97: 1271-1276, 2007.

9. El-Mesallamy HO, Hegab HM and Kamal AM: Expression of inhibitor of apoptosis protein (IAP) livin/BIRC7 in acute leukemia in adults: correlation with prognostic factors and outcome. Leuk Res 35: 1616-1622, 2011.

10. Stewart DJ: Tumor and host factors that may limit efficacy of chemotherapy in non-small cell and small cell lung cancer. Crit Rev Oncol Hematol 75: 173-234, 2010.

11. Hariu H, Hirohashi Y, Torigoe T, et al: Aberrant expression and potency as a cancer immunotherapy target of inhibitor of apoptosis protein family, Livin/ML-IAP in lung cancer. Clin Cancer Res 11: 1000-1009, 2005.

12. Chen N, Gong J, Chen X, et al: Caspases and inhibitor of apoptosis proteins in cutaneous and mucosal melanoma: expression profile and clinicopathologic significance. Hum Pathol 40: 950-956, 2009.

13. Wang TS, Ding QQ, Guo RH, et al: Expression of livin in gastric cancer and induction of apoptosis in SGC-7901 cells by shRNAmediated silencing of livin gene. Biomed Pharmacother 64: 333-338, 2010.

14. Crnkovic-Mertens I, Wagener N, Semzow J, et al: Targeted inhibition of Livin resensitizes renal cancer cells towards apoptosis. Cell Mol Life Sci 64: 1137-1144, 2007.

15. Crnkovic-Mertens I, Hoppe-Seyler F and Butz K: Induction of apoptosis in tumor cells by siRNA-mediated silencing of the livin/ML-IAP/KIAP gene. Oncogene 22: 8330-8336, 2003.

16. Yagihashi A, Asanuma K, Tsuji N, et al: Detection of anti-livin antibody in gastrointestinal cancer patients. Clin Chem 49: 1206-1208, 2003.

17. Yagihashi A, Asanuma K, Kobayashi D, et al: Detection of autoantibodies to livin and survivin in Sera from lung cancer patients. Lung Cancer 48: 217-221, 2005.

18. Engelhardt JJ, Boldajipour B, Beemiller P, et al: Marginating dendritic cells of the tumor microenvironment cross-present tumor antigens and stably engage tumor-specific $\mathrm{T}$ cells. Cancer Cell 21: 402-417, 2012.

19. Steinman RM and Banchereau J: Taking dendritic cells into medicine. Nature 449: 419-426, 2007.

20. Atanackovic D, Luetkens T, Kloth B, et al: Cancer-testis antigen expression and its epigenetic modulation in acute myeloid leukemia. Am J Hematol 86: 918-922, 2011.

21. Seo MJ, Kim GR, Son YM, et al: Interactions of dendritic cells with cancer cells and modulation of surface molecules affect functional properties of $\mathrm{CD}^{+} \mathrm{T}$ cells. Mol Immunol 48: 1744-1752, 2011.

22. Kakimi K, Nakajima J and Wada H: Active specific immunotherapy and cell-transfer therapy for the treatment of non-small cell lung cancer. Lung Cancer 65: 1-8, 2009.

23. Brenner MK and Heslop HE: Adoptive T cell therapy of cancer. Curr Opin Immunol 22: 251-257, 2010.

24. Han P, Hodge G, Story C and Xu X: Phenotypic analysis of functional T-lymphocyte subtypes and natural killer cells in human cord blood: relevance to umbilical cord blood transplantation. $\mathrm{Br}$ J Haematol 89: 733-740, 1995.

25. Germenis AE and Karanikas V: Cord blood as a source of nonsenescent lymphocytes for tumor immunotherapy. J Reprod Immunol 85: 47-50, 2010.

26. Brown JA and Boussiotis VA: Umbilical cord blood transplantation: basic biology and clinical challenges to immune reconstitution. Clin Immunol 127: 286-297, 2008.

27. Brunstein CG, Gutman JA, Weisdorf DJ, et al: Allogeneic hematopoietic cell transplantation for hematologic malignancy: relative risks and benefits of double umbilical cord blood. Blood 116: 4693-4699, 2010

28. Xie J, Xiong L, Tao X, et al: Antitumor effects of murine bone marrow-derived dendritic cells infected with xenogeneic livin alpha recombinant adenoviral vectors against Lewis lung carcinoma. Lung Cancer 68: 338-345, 2010.

29. Antonia SJ, Mirza N, Fricke I, et al: Combination of p53 cancer vaccine with chemotherapy in patients with extensive stage small cell lung cancer. Clin Cancer Res 12: 878-887, 2006.

30. Anderson RJ and Schneider J: Plasmid DNA and viral vectorbased vaccines for the treatment of cancer. Vaccine 25: B24-B34, 2007. 
31. Ljunggren HG and Malmberg KJ: Prospects for the use of NK cells in immunotherapy of human cancer. Nat Rev Immunol 7: 329-339, 2007.

32. Guiducci C, Vicari AP, Sangaletti S, Trinchieri G and Colombo MP Redirecting in vivo elicited tumor infiltrating macrophages and dendritic cells towards tumor rejection. Cancer Res 65: $3437-$ 3446, 2005.

33. Xu RL, Tang Y, Ogburn PL, et al: Implication of delayed TNF-alpha exposure on dendritic cell maturation and expansion from cryopreserved cord blood $\mathrm{CD} 34^{+}$hematopoietic progenitors. J Immunol Methods 293: 169-182, 2004.

34. Safdar A, Decker WK, Li S, et al: De novo T-lymphocyte responses against baculovirus-derived recombinant influenzavirus hemagglutinin generated by a naive umbilical cord blood model of dendritic cell vaccination. Vaccine 27: 1479-1484, 2009.

35. Mainali ES and Tew JG: Dexamethasone selectively inhibits differentiation of cord blood stem cell derived-dendritic cell (DC) precursors into immature DCs. Cell Immunol 232: 127-136, 2004.

36. Gansuvd B, Hagihara M, Higuchi A, et al: Umbilical cord blood dendritic cells are a rich source of soluble HLA-DR: synergistic effect of exosomes and dendritic cells on autologous or allogeneic T-Cell proliferation. Hum Immunol 64: 427-439, 2003.

37. Tang XD, Wan Y, Chen L, et al: H-2Kb-restricted CTL epitopes from mouse heparanase elicit an antitumor immune response in vivo. Cancer Res 68: 1529-1537, 2008.

38. Oku M, Okumi M, Sahara H, et al: Porcine CFSE mixed lymphocyte reaction and PKH-26 cell-mediated lympholysis assays. Transpl Immunol 20: 78-82, 2008.

39. Luo F, Song X, Zhang Y and Chu Y: Low-dose curcumin leads to the inhibition of tumor growth via enhancing CTL-mediated antitumor immunity. Int Immunopharmacol 11: 1234-1240, 2011.

40. Hsieh $\mathrm{CH}$, Huang YC, Tsai TH and Chen YJ: Cantharidin modulates development of human monocyte-derived dendritic cells. Toxicol In Vitro 25: 1740-1747, 2011.

41. Cholujova D, Jakubikova J, Kubes M, et al: Comparative study of four fluorescent probes for evaluation of natural killer cell cytotoxicity assays. Immunobiology 213: 629-640, 2008.

42. Disis ML, Bernhard H and Jaffee EM: Use of tumour-responsive T cells as cancer treatment. Lancet 373: 673-683, 2009.

43. Seki N, Brooks AD, Carter CR, et al: Tumor-specific CTL kill murine renal cancer cells using both perforin and Fas ligandmediated lysis in vitro, but cause tumor regression in vivo in the absence of perforin. J Immunol 168: 3484-3492, 2002.
44. Caldwell SA, Ryan MH, McDuffie E and Abrams SI: The Fas/ Fas ligand pathway is important for optimal tumor regression in a mouse model of CTL adoptive immunotherapy of experimental CMS4 lung metastases. J Immunol 171: 2402-2412, 2003.

45. Begley J and Ribas A: Targeted therapies to improve tumor immunotherapy. Clin Cancer Res 14: 4385-4391, 2008.

46. Smith SG, Patel PM, Selby PJ and Jackson AM: The response of human dendritic cells to recombinant adenovirus, recombinant Mycobacterium bovis Bacillus Calmette Guerin and biolistic methods of antigen delivery: different induction of contactdependant and soluble signals. Immunol Lett 76: 79-88, 2001.

47. Yee C: Adoptive T cell therapy: addressing challenges in cancer immunotherapy. J Transl Med 3: 17, 2005.

48. Xing W, Wu S, Yuan X, et al: The anti-tumor effect of human monocyte-derived dendritic cells loaded with HSV-TK/GCV induced dying cells. Cell Immunol 254: 135-141, 2009.

49. Wojas-Krawczyk K, Krawczyk P, Buczkowski J, et al: Immunotherapy of lung adenocarcinoma patient with Peptidepulsed dendritic cells: a case report. Arch Immunol Ther Exp 60: 69-77, 2012.

50. Prasad S, Cody V, Saucier-Sawyer JK, et al: Polymer nanoparticles containing tumor lysates as antigen delivery vehicles for dendritic cell-based antitumor immunotherapy. Nanomedicine 7: 1-10, 2011.

51. Lucas S and Coulie PG: About human tumor antigens to be used in immunotherapy. Semin Immunol 20: 301-307, 2008.

52. Beebe M, Qin MS, Moi M, et al: Formulation and characterization of a ten-peptide single-vial vaccine, EP-2101, designed to induce cytotoxic T-lymphocyte responses for cancer immunotherapy. Hum Vaccin 4: 210-218, 2008.

53. Spiotto MT, Fu YX and Schreiber H: Tumor immunity meets autoimmunity: antigen levels and dendritic cell maturation. Curr Opin Immunol 15: 725-730, 2003.

54. Yang JY, Cao DY, Liu WC, Zhang HM, Teng ZH and Ren J: Dendritic cell generated from $\mathrm{CD} 34^{+}$hematopoietic progenitors can be transfected with adenovirus containing gene of $\mathrm{HBsAg}$ and induce antigen-specific cytotoxic $\mathrm{T}$ cell responses. Cell Immunol 240: 14-21, 2006.

55. Dianzani U, Chiocchetti A and Ramenghi U: Role of inherited defects decreasing Fas function in autoimmunity. Life Sci 72: 2803-2824, 2003. 